\title{
Characterization of Lanthanum(III) Chromium(V) Tetraoxide by X-Ray Photoelectron Spectroscopy
}

\author{
Hidetaka Konno, Hiroto Tachikawa, Atsushi Furusaki and Ryusaburo Furuichi
}

Faculty of Engineering, Hokkaido University, Sapporo 060, Japan

\begin{abstract}
Lanthanum(III) chromium(V) tetraoxide, $\mathrm{LaCrO}_{4}$, was synthesized by a thermal decomposition method and characterized by X-ray photoelectron spectroscopy and ab initio molecular orbital calculations. The chromium(V) state in $\mathrm{LaCrO}_{4}$ is stable in both air and vacuum. The electron binding energies, $E_{\mathrm{B}}$, and Auger parameters, $\alpha$, of $\mathrm{Cr}(\mathrm{V})$ and $\mathrm{La}(\mathrm{III})$ indicated that the covalency of the $\mathrm{Cr}-\mathrm{O}$ bonds in $\mathrm{CrO}_{4}$ tetrahedra is higher than that in $\mathrm{CrO}_{6}$ octahedra of $\mathrm{LaCrO}_{3}$, and that $\mathrm{La}(\mathrm{III})$ in $\mathrm{LaCrO}_{4}$ is more ionic than in $\mathrm{LaCrO}_{3}$. The results of a $b$ initio molecular orbital calculations agreed with the measured characteristics, that is, the electrons are flowing from oxygen to $\mathrm{Cr}(\mathrm{V})$ and the covalency plays a significant part in the $\mathrm{Cr}-\mathrm{O}$ bonds. This behavior of the $\mathrm{Cr}-\mathrm{O}$ bond was considered to contribute to stabilizing $\mathrm{CrO}_{4}{ }^{3-}$ tetrahedra.
\end{abstract}

Keywords Lanthanum(III) chromium(V) monazite type oxide, lanthanum(III) chromium(III) perovskite type oxide, $\mathrm{X}$-ray photoelectron spectroscopy, ab initio molecular orbital calculation

Lanthanum chromium tetraoxide, $\mathrm{LaCrO}_{4}$, is one of a few $\mathrm{Cr}(\mathrm{V})$ compounds which are stable and which can be isolated. The compound can be synthesized by thermal decomposition of $\mathrm{La}_{2}\left(\mathrm{CrO}_{4}\right)_{3}{ }^{1}$ or $\mathrm{LaCr}\left(\mathrm{C}_{2} \mathrm{O}_{4}\right)_{3} \cdot 9 \mathrm{H}_{2} \mathrm{O}^{2,3}$ It has a monoclinic structure, space group $P 2_{1} / n^{3}$, similar to monazite and is paramagnetic due to a single unpaired electron on $\mathrm{Cr}(\mathrm{V})$, which can be characterized by EPR. ${ }^{2}$ The X-ray photoelectron spectroscopy, XPS, measurements of the title compound will provide important information on the electronic configuration of $\mathrm{Cr}(\mathrm{V})$ or $\mathrm{CrO}_{4}{ }^{3-}$ state that will be useful for understanding chemical properties of $\mathrm{Cr}(\mathrm{V})$ species. The X-ray photoelectron spectroscopic data on $\operatorname{Cr}(\mathrm{V})$ is only reported with $\mathrm{Na}_{3} \mathrm{CrO}_{4}{ }^{4}$ which is less stable and more difficult to handle than $\mathrm{LaCrO}_{4}$. Due to the low stability of the sodium compound, the $\mathrm{Cr} 2 \mathrm{p}$ spectrum is distorted and the reported electron binding energies, $E_{\mathrm{B}}$, of $\mathrm{Cr} 3 \mathrm{~s}$ and $\mathrm{Cr} 3 \mathrm{p}$ are not accurate, with uncertainties of $\pm 0.5 \mathrm{eV}$.

We have found that the title compound can be simply formed as a single phase during the synthesis of perovskite structure $\mathrm{LaCrO}_{3}$ from precursors prepared with $\mathrm{La}$ (III)-Cr(VI) equimolar mixed solutions and that the compound is stable at $600^{\circ} \mathrm{C}$ in air for $12 \mathrm{~h} .^{5}$ In the present work, $E_{\mathrm{B}}$ values of $\mathrm{Cr}, \mathrm{La}$, and $\mathrm{O}$ including Auger parameters, $\alpha$, and the valence band spectrum for $\mathrm{LaCrO}_{4}$ were measured, and the characteristics of the chemical bonds between $\mathrm{La}, \mathrm{Cr}$, and $\mathrm{O}$ are examined. The electron binding energies for $\mathrm{LaCrO}_{3}$ are also reported.

\section{Experimental}

The title compound, $\mathrm{LaCrO}_{4}$, was formed by thermal decomposition of a precursor for $1 \mathrm{~h}$ at $600^{\circ} \mathrm{C}$ in air; the precursor was prepared by vacuum condensation of an equimolar solution of $\mathrm{La}\left(\mathrm{CH}_{3} \mathrm{COO}\right)_{3}$ and $\mathrm{CrO}_{3}$ at $70^{\circ} \mathrm{C}$, followed by preheating at $400^{\circ} \mathrm{C}$ in air. Details are reported elsewhere. ${ }^{5}$ The XRD pattern and EPR spectrum of the formed $\mathrm{LaCrO}_{4}$ coincided with the reported data $^{2,3}$ and are shown elsewhere. ${ }^{5}$

The X-ray photoelectron spectroscopic measurements were carried out by a VG Scientific ESCALAB MkII. The samples were embedded in indium foil on a holder or pressed on a nickel mesh welded on a holder. In a vacuum better than $10^{-8} \mathrm{~Pa}$, the samples were irradiated with $\mathrm{Al} \mathrm{K} \mathrm{K}_{\alpha} \mathrm{X}$-ray $(15 \mathrm{kV}, 10-20 \mathrm{~mA})$. The analyzer pass energy was set at $20 \mathrm{eV}$ which gave a $1.20 \mathrm{eV}$ full width at half maximum, FWHM, of the $\mathrm{Au} \mathbf{4} \mathbf{f}_{7 / 2}$ spectra for a sputter-cleaned gold foil; only in the energy region of $\mathrm{O}_{\mathrm{KLL}}$ and $\mathrm{Cr}_{\mathrm{LMM}}$ was the analyzer pass energy set at $50 \mathrm{eV}$.

In some measurements, the charge up shift of less than $2 \mathrm{eV}$ was observed for $\mathrm{LaCrO}_{3}$, but no peak broadening was observed. The binding energies were calibrated with $E_{\mathrm{B}}\left[\mathrm{Au} 4 \mathrm{f}_{7 / 2}\right]=84.0 \mathrm{eV}$ for gold particles sputterdeposited on the samples: with some samples $E_{\mathrm{B}}[\mathrm{C} 1 \mathrm{~s}]=$ $284.6 \mathrm{eV}$ for surface contaminants calibrated by $E_{\mathrm{B}}[\mathrm{Au}$ $4 f_{7 / 2}$ ] was used as a calibrant. The linearity of the energy scale of the spectrometer was confirmed with the $\mathrm{Cu} 3 \mathrm{p}$, $\mathrm{Cu} 3 \mathrm{~s}, \mathrm{Cu} 2 \mathrm{p}$, and $\mathrm{Au} 4 \mathrm{f}$ peaks. The measurements were repeated at least twice for three samples from different 
batches. The X-ray satellites from $\mathrm{Al} \mathrm{K} \mathrm{K}_{\alpha 3,4}$ and $\mathrm{Al} \mathrm{K_{ \beta }}$ were subtracted by the VGS 5250 data system. The binding energies were determined by assuming that symmetrical Gaussian-Lorentzian mixed functions fit each component of the spectra after subtracting the background by the Shirley method. ${ }^{6}$ Although this procedure, as pointed out, is only an approximation ${ }^{7}$, the estimated $E_{\mathrm{B}}$ values are not affected beyond the limits of experimental error. It is, however, necessary to be aware that peak intesities may be misleading. The kinetic energies of Auger peaks were determined from the maximum counting rate position.

Molecular orbital calculations were carried out for $\left[\mathrm{CrO}_{4}\right]^{n-}$ clusters by the $a b$ initio restricted open shell Hartree-Fock (ROHF) method. ${ }^{8,9}$ The basis sets employed were Huzinaga's (3333/33/3) for the chromium atoms ${ }^{10}$ and the $(631 / 31)$ +diffuse (sp) function (exponent= $0.0845)$ for the oxygen atoms. ${ }^{11}$ Ionization energies were estimated from Koopmans' theorem. ${ }^{12}$ The multireference single and double excitation configuration interaction (MR-SD-CI) calculation ${ }^{13}$ was also used to determine the electronic states of the clusters. All calculations were performed by a HITAC S820 supercomputer at the Institute for Molecular Science (IMS) in Okazaki.

\section{Results and Discussion}

\section{Core electron spectra}

The binding energy, $E_{\mathrm{B}}$, data of core electrons are summarized in Table 1 together with the Auger parameters, $\alpha$.

The $\mathrm{LaCrO}_{4}$ was stable in a vacuum of $10^{-8} \mathrm{~Pa}$, and no spontaneous decomposition of $\mathrm{Cr}(\mathrm{V})$ to $\mathrm{Cr}$ (III) were observed for $90 \mathrm{~h}$; decomposition is usually seen with $\mathrm{Cr}$ (VI) compounds. Figure 1 shows the $\mathrm{Cr} 2 \mathrm{p}$ spectrum for $\mathrm{LaCrO}_{4}$ after $90 \mathrm{~h}$ in a spectrometer vacuum; the spectrum for $\mathrm{LaCrO}_{3}$ is also shown. The values of $E_{\mathrm{B}}[\mathrm{Cr} 2 \mathrm{p}]$ and spin orbit splitting for $\mathrm{LaCrO}_{4}$ are in agreement with those for $\mathrm{Na}_{3} \mathrm{CrO}_{4}{ }^{4}$ within the limits of experimental error, after correcting by $E_{\mathrm{B}}\left[\mathrm{Au} 4 \mathrm{f}_{7 / 2}\right]=$ $84.0 \mathrm{eV}$. Full width at half maximum, FWHM, of $\mathrm{Cr} 2 \mathrm{p}_{3 / 2}$ peak was $2.50 \pm 0.12 \mathrm{eV}( \pm 1 \sigma)$ and slightly wider than FWHM $\sim 2.3 \mathrm{eV}$ for the $\mathrm{Cr}(\mathrm{VI})$ precursor, but much narrower than that for $\mathrm{LaCrO}_{3}$ (cf. Fig. 1). The shape of the spectrum for $\mathrm{LaCrO}_{4}$ is similar to that for $\mathrm{Cr}$ (VI) compounds, except that weak satellites are present at about $5.5 \mathrm{eV}$ higher $E_{\mathrm{B}}$ position than the main peaks. This feature was not observed with $\mathrm{Na}_{3} \mathrm{CrO}_{4}$, probably due to poor resolution and distortion of the spectrum. ${ }^{4}$ The appearance of the satellites is likely, as $\mathrm{Cr}(\mathrm{V})$ species have a $3 \mathrm{~d}^{1}$ configuration and $\mathrm{LaCrO}_{4}$ has $1.79 \mathrm{BM}$ at $300 \mathrm{~K}^{2}{ }^{2}$ In the $\mathrm{Cr} 3 \mathrm{~s}$ spectrum for $\mathrm{LaCrO}_{4}$, multiplet splitting was not observed (Fig. 2(A)), whereas for $\mathrm{LaCrO}_{3}$ this was $4.0 \mathrm{eV}$ (Fig. 2(B)). Full width at half maximum of the $\mathrm{Cr} 3 \mathrm{~s}$ peak for $\mathrm{LaCrO}_{4}$ was $4.70 \pm$ $0.39 \mathrm{eV}( \pm 1 \sigma)$, around $10 \%$ broadened relative to the $\mathrm{Cr}(\mathrm{VI})$ precursor, so that the presence of a hidden peak is
Table 1 Electron binding energies, $E_{\mathrm{B}}$, and kinetic energies of Auger electrons, $E_{\mathrm{K}}$, in $\mathrm{eV}$

\begin{tabular}{|c|c|c|}
\hline & $\mathrm{LaCrO}_{4}$ & $\mathrm{LaCrO}_{3}$ \\
\hline $\mathrm{Cr} 3 p$ & $46.4(0.07)$ & $43.2(0.17)$ \\
\hline $\mathrm{Cr} 3 \mathrm{~s}$ & $77.8(0.30)$ & $74.4(0.06)$ \\
\hline multiplet satellite & none & $78.4(0.28)$ \\
\hline $\operatorname{Cr} 2 p_{3 / 2}$ & $578.8(0.21)$ & $576.1(0.09)$ \\
\hline $2 p_{1 / 2}$ & $588.0(0.22)$ & $585.8(0.05)$ \\
\hline spin orbital splitting & 9.2 & 9.7 \\
\hline $\mathrm{Cr}_{\mathrm{L3M} 23 \mathrm{M} 45^{\mathrm{a}}}$ & $529.6(0.21)$ & $529.8(0.14)$ \\
\hline$\alpha_{\mathrm{Cr}}\left[\mathrm{Cr} 2 \mathrm{p}_{3 / 2}+\mathrm{Cr}_{\mathrm{LMM}}\right]$ & 1108.4 & 1105.9 \\
\hline $\mathbf{L a ~} 4 d_{5 / 2}$ & $102.2(0.33)$ & $101.5(0.15)$ \\
\hline $4 d_{3 / 2}$ & $105.2(0.33)$ & $104.7(0.20)$ \\
\hline spin orbit splitting & 3.0 & 3.2 \\
\hline $\mathrm{La} 3 \mathrm{~d}_{5 / 2}$ & $834.9(0.19)$ & $834.2(0.21)$ \\
\hline satellite & $838.6(0.17)$ & $838.0(0.28)$ \\
\hline $3 d_{3 / 2}$ & $851.8(0.17)$ & $851.1(0.15)$ \\
\hline satellite & $855.5(0.18)$ & $854.8(0.06)$ \\
\hline spin orbit splitting & 16.9 & 16.9 \\
\hline $\mathrm{La}_{\mathrm{M} 5 \mathrm{~N} 45 \mathrm{~N} 45^{\mathrm{a}}}$ & $622.3(0.24)$ & $623.0(0.71)$ \\
\hline$\alpha_{\mathrm{La}}\left[\mathrm{La} 3 \mathrm{~d}_{5 / 2}+\mathrm{La}_{\mathrm{MNN}}\right]$ & 1457.2 & 1457.2 \\
\hline 0 is & $529.8(0.29)$ & $529.5(0.23)$ \\
\hline $\mathrm{O}_{\mathbf{K L L}}{ }^{\mathbf{a}}$ & $512.8(0.12)$ & $512.9(0.56)$ \\
\hline$\alpha_{\mathrm{o}}\left[\mathrm{O} 1 \mathrm{~s}+\mathrm{O}_{\mathrm{KLL}}\right]$ & 1042.6 & 1042.4 \\
\hline
\end{tabular}

a. Kinetic energy. Uncertainties in parentheses are $1 \sigma$ in $\mathrm{eV}$.

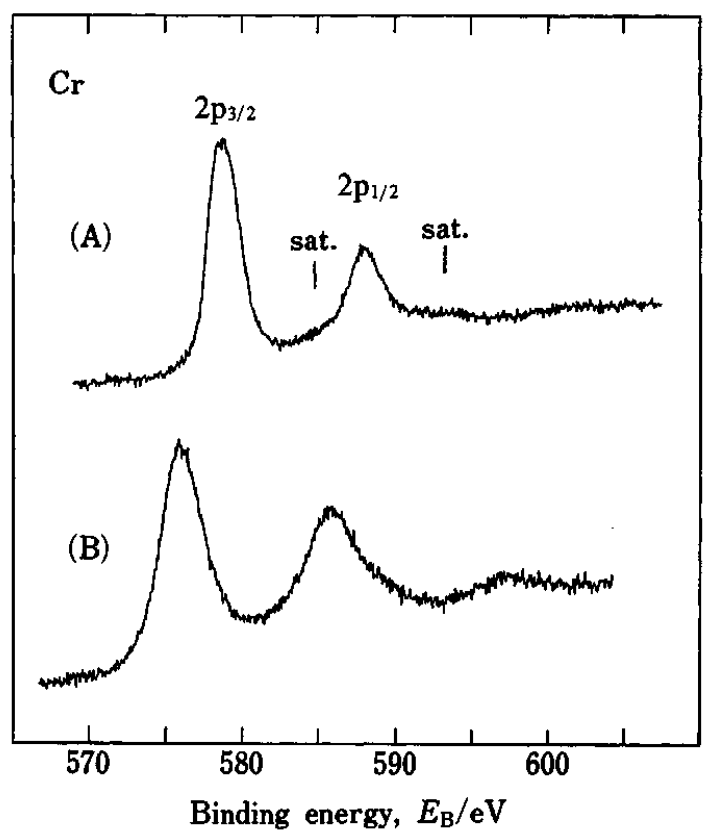

Fig. 1 X-Ray photoelectron spectra of $\mathrm{Cr} 2 \mathrm{p}$ for (A) $\mathrm{LaCrO}_{4}$ and (B) $\mathrm{LaCrO}_{3}$. Satellite peaks are indicated only for $\mathrm{LaCrO}_{4}$.

unlikely. The disappearance of multiplet splitting may be caused by: (1) single unpaired electron in the $3 \mathrm{~d}$ orbital, and (2) delocalization or coupling. Absent multiplet splitting suggests that the covalency of the $\mathrm{Cr}-\mathrm{O}$ bond is high in the $\mathrm{CrO}_{4}$ tetrahedral structure for $\mathrm{LaCrO}_{4}$. This will be discussed in the following section. 


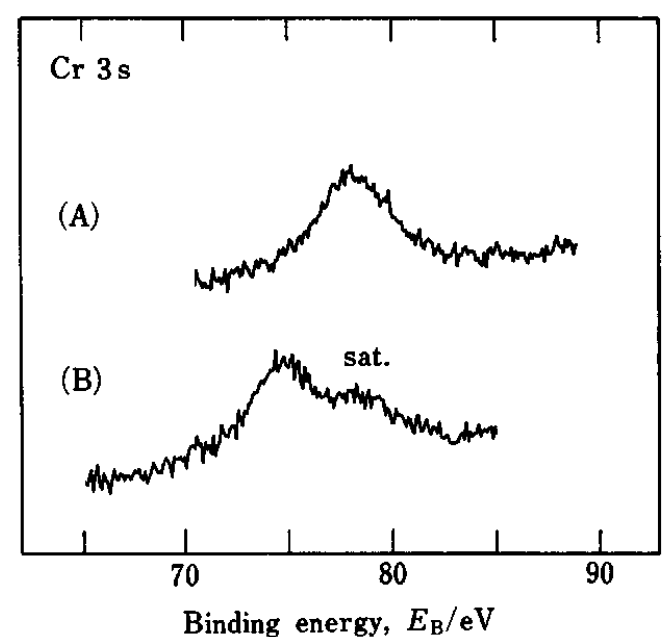

Fig. 2 X-Ray photoelectron spectra of $\mathrm{Cr} 3 \mathrm{~s}$ for (A) $\mathrm{LaCrO}_{4}$ and (B) $\mathrm{LaCrO}_{3}$. Sat. indicates a multiplet satellite.

The peak broadening and the satellites in the $\mathrm{Cr} 2 \mathrm{p}$ spectra for $\mathrm{Cr}(\mathrm{III})$ and $\mathrm{Cr}(\mathrm{IV})$ compounds are often attributed to the effect of multiplet splitting. ${ }^{14}$ Our results, however, suggest that the observed satellites in $\mathrm{Cr} 2 \mathrm{p}$ for $\mathrm{LaCrO}_{4}$ may be due to a shake-up process, as reported for $\mathrm{LaCrO}_{3 .}{ }^{15}$

The peak position of $\mathrm{Cr}_{\mathrm{L}_{3 \mathrm{M} 23 \mathrm{M} 45}}$ is often ambiguous under the influence of the $\mathrm{O}_{\mathrm{KL} L 2 \mathrm{~L} L 23}$ peak. Here, in order to make the peak positions distinctive, linear background subtraction was done as shown in Fig. 3. The Auger parameter, $\alpha_{\mathrm{Cr}}=E_{\mathrm{B}}\left[\mathrm{Cr} 2 \mathrm{p}_{3 / 2}\right]+E_{\mathrm{K}}\left[\mathrm{Cr}_{1 \text {-3м23M45 }}\right]$, for $\mathrm{LaCrO}_{4}$ was $2.5 \mathrm{eV}$ larger than for $\mathrm{LaCrO}_{3}$, due to the differences in $E_{\mathrm{B}}\left[\mathrm{Cr} 2 \mathrm{p}_{3 / 2}\right]$ values. The results indicate that the extra-atomic relaxation energy is higher for $\mathrm{LaCrO}_{4}$ than for $\mathrm{LaCrO}_{3}$, and suggests that the electrons are flowing from oxygen to chromium, in agreement with the disappearance of the multiplet splitting.

Both $E_{\mathrm{B}}[\mathrm{La}]$ and $E_{\mathrm{K}}\left[\mathrm{La}_{\mathrm{MNN} 45 \mathrm{~N} 45}\right]$ for $\mathrm{LaCrO}_{4}$ were comparable to those for $\mathrm{La}_{2} \mathrm{O}_{3} ;{ }^{16}$ the $E_{\mathrm{B}}$ values were about $0.7 \mathrm{eV}$ higher than for $\mathrm{LaCrO}_{3}$ (Table 1). Using La 3d spectra, Berthou et al..$^{17}$ reported that the covalency of the chemical bond between La(III) and the ligand is proportional to the intensity of the satellite. They reported satellite-to-main-peak intensity ratios for a series of La compounds by peak height, and a $I$ [sat.]/ $I\left[\mathrm{La} 3 \mathrm{~d}_{5 / 2}\right]$ of 0.95 for $\mathrm{LaCrO}_{3}$ and 0.86 for $\mathrm{La}_{2} \mathrm{O}_{3}$. We also measured the intensity ratio for $\mathrm{LaCrO}_{3}$ both by height and area, but did not obtain such high values. Estimated by area, our ratio for $\mathrm{LaCrO}_{3}$ was below 0.80 and around 0.77 for $\mathrm{LaCrO}_{4}$, depending on the limitations in peak separation. Berthou et al. indicated that the covalency to intensity ratio is a much better indicator of the covalent bond than the satellite energy separations, but they did not provide theoretical justification. For the present discussion, it is not appropriate to consider the characteristics of the chemical bond between $\mathrm{La}$ (III) and the $\mathrm{CrO}_{4}$ group based on the intensity ratio.

The lanthanum atom in monoclinic $\mathrm{LaCrO}_{4}$ is asym-

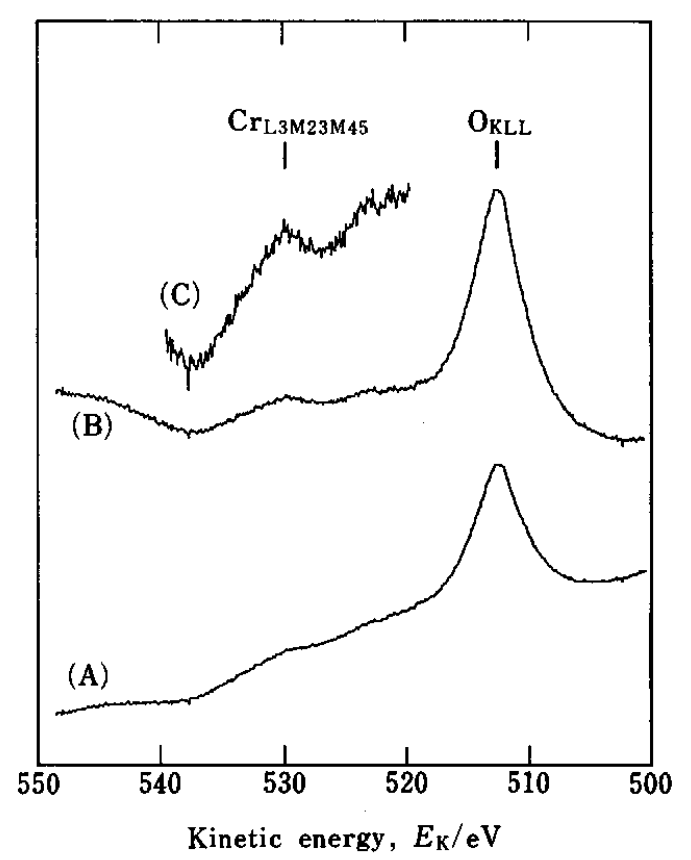

Fig. 3 X-Ray photoelectron spectra of $\mathrm{Cr}_{\mathrm{LMM}}$ and $\mathrm{O}_{\mathrm{KLL}}$ region for $\mathrm{LaCrO}_{4}$. (A) original spectrum, (B) (A) after linear background subtraction, and $(\mathrm{C})$ enlarged $\mathrm{Cr}_{\mathrm{LMM}}$ region of (B).

metrically surrounded by six $\mathrm{CrO}_{4}$ tetrahedra (La coordination number $=9$ ), whereas that in orthorhombic $\mathrm{LaCrO}_{3}$ is the center of eight $\mathrm{CrO}_{6}$ octahedra (La coordination number $=12$ ). From this structural difference and the differences in $E_{\mathrm{B}}$ for $\mathrm{La}(\mathrm{III})$, it is probable that $\mathrm{La}$ (III) in $\mathrm{LaCrO}_{4}$ is more ionic than in $\mathrm{LaCrO}_{3}$. The absence of differences between $\alpha_{\mathrm{La}}$ values also indicates that the differences in $E_{\mathrm{B}}$ values can be attributed to the initial state effects.

There is some uncertainty in the spin orbit separation of La $4 \mathrm{~d}$ due to the peak separation. Howng and Thorn ${ }^{18}$ reported that $\mathrm{La} 4 \mathrm{~d}$ peak can be separated into La $\mathbf{4 d}_{5 / 2}$ and $\mathrm{La} \mathbf{4 d}_{3 / 2}$ each having a satellite. However, they provide neither criteria for separating the peaks nor a method of background subtraction; but their intensity

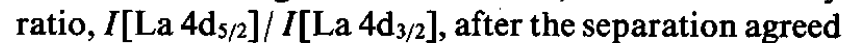
with the theoretical value reported by Burroughs et al. ${ }^{19}$ This agreement, however, does not verify the correctness of their peak separation, since the total intensity ratio including satellites should be compared. We found that at least one limiting condition is necessary to separate the La 4d peaks; the limiting condition may be the same FWHM for the peak pair, the same Gaussian-Lorentzian mixing ratio, a certain fixed splitting between the main peak and the satellite, or some similar one. Here, the calculations were carried out by using one value of Gaussian-Lorentzian mixing ratio for the main peak pair and another value for the satellite pair. The results where the total intensity ratio including satellites agreed with a calculated cross section ratio ${ }^{20}$ were taken as the final values. An example of the results is shown in 
Fig. 4.

The values of $E_{\mathrm{B}}[\mathrm{Cr} 2 \mathrm{p}]$ for $\mathrm{LaCrO}_{3}$ are in agreement with those reported by Howng and Thorn ${ }^{15}$ after correcting by $E_{\mathrm{B}}\left[\mathrm{Au} 4 \mathrm{f}_{7 / 2}\right]=84.0 \mathrm{eV}$ but other $E_{\mathrm{B}}$ values in Table 1 do not agree with their results. One reason is that they used $E_{\mathrm{B}}[\mathrm{C} 1 \mathrm{~s}]$ value for contamination as a reference peak even after ion sputtering: this is not an appropriate, since the $E_{\mathrm{B}}[\mathrm{C}$ 1s] value for contamination changes due to ion sputtering. The large differences in measured $E_{\mathrm{B}}[\mathrm{Cr} 3 \mathrm{p}], E_{\mathrm{B}}[\mathrm{Cr} 3 \mathrm{~s}], E_{\mathrm{B}}[\mathrm{La} 4 \mathrm{~d}]$, and $E_{\mathrm{B}}[\mathrm{La} 3 \mathrm{~d}]$ values cannot be explained by this alone. The differences may be explained by the following: (1) there are many misprints and inconsistencies in the values in tables, figures, and text in the papers; ${ }^{15,19}$ (2) for $\mathrm{Cr}_{2} \mathrm{O}_{3}$, the $E_{\mathrm{B}}[\mathrm{Cr} 2 \mathrm{p}]$ values agree with those reported by others ${ }^{16,21,22}$, but the $E_{\mathrm{B}}[\mathrm{Cr} 3 \mathrm{~s}]$ value is about $1 \mathrm{eV}$ higher than other data; 21,22 and (3) for $\mathrm{La}_{2} \mathrm{O}_{3}$, the $E_{\mathrm{B}}[\mathrm{La} 3 \mathrm{~d}]$ values are about $2 \mathrm{eV}$ lower than data reported elsewhere. ${ }^{16}$

\section{Valence band spectra and calculated electronic states}

The valence band for $\mathrm{LaCrO}_{4}$ starts from $E_{\mathrm{B}} \sim 7.5 \mathrm{eV}$, which is about $9.5 \mathrm{eV}$ above $\mathrm{La} 5 \mathrm{p}_{3 / 2}$, and it extends to the Fermi edge, as shown in Fig. 5. There is a low density band just below the Fermi edge; the presence of the low density band is supported by the reproducible shape of the valence band spectrum. The peak positions of La 5p and $\mathrm{O} 2 \mathrm{~s}$ are distinguishable without peak separation and no photoemission is observable between these peaks and the valence band, so it is unlikely that there is an interaction between them.

For $a b$ initio ROHF-MO calculations ${ }^{8,9}$, the following assumptions were made as a first approximation: (1) the calculations are possible with the one unit model, the $\mathrm{CrO}_{4}{ }^{3-}$ cluster, since, as mentioned above, the ionic character of $\mathrm{La}(\mathrm{III})$ for $\mathrm{LaCrO}_{4}$ is comparable to that for $\mathrm{La}_{2} \mathrm{O}_{3}(>75 \%)$; and (2) the molecular symmetry of the cluster is $T_{d}$ and the $\mathrm{Cr}-\mathrm{O}$ bond length is $0.16 \mathrm{~nm}$. The latter was assumed based on the structure of similar monazite type minerals. ${ }^{23}$ The accurate atomic arrangement of $\mathrm{LaCrO}_{4}$ is not established, though the Xray diffraction data has been reported. ${ }^{3}$ The absolute energy positions of the calculated molecular orbitals depend on the $\mathrm{Cr}-\mathrm{O}$ bond length, but, the order of the orbitals from the Fermi edge need not change with the assumed $\mathrm{Cr}-\mathrm{O}$ bond lengths allowed for this cluster.

The calculated contour maps for singly occupied molecular orbitals of the $\mathrm{CrO}_{4}{ }^{3-}$ cluster are shown in Fig. 6. The maps indicate that the spin orbital is composed of an antibonding $\pi^{*}\left(\mathrm{dz}^{2}-2 \mathrm{p}\right)$ orbital which is formed by interaction between $\mathrm{Cr}\left(\mathrm{dz}^{2}\right)$ and $\mathrm{O}(2 \mathrm{p})$ orbitals. The electronic configurations in the valence band were calculated to be

$\left(3 d z^{2}\right)^{1.13}\left(3 d x^{2}-y^{2}\right)^{0.72}(3 d x y)^{0.44}(3 d y z)^{0.72}(3 d z x)^{0.72}(4 s)^{0.078}$.

This means that the population of electrons on the $\mathrm{dz}^{2}$ orbital of $\mathrm{Cr}$ is larger than on other orbitals, indicating that an unpaired electron is occupying the $\mathrm{dz}^{2}$ orbital.

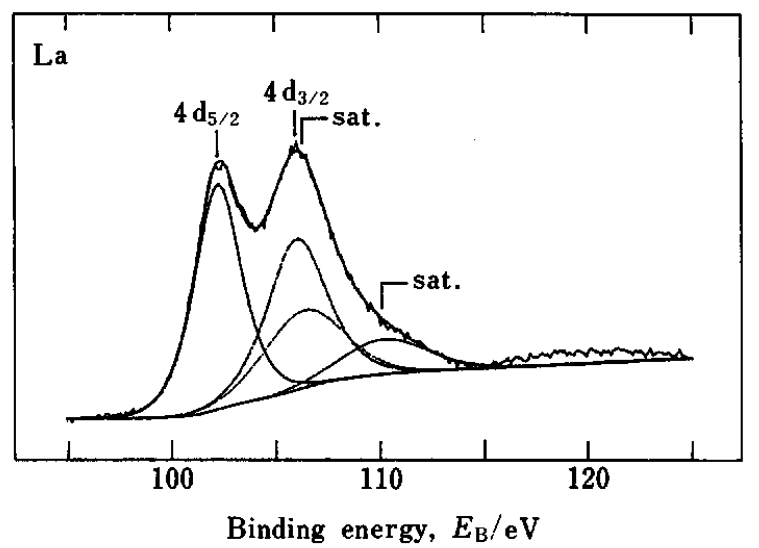

Fig. 4 An example of peak separation of $\mathrm{La} 4 \mathrm{~d}$ spectrum for $\mathrm{LaCrO}_{4}$.

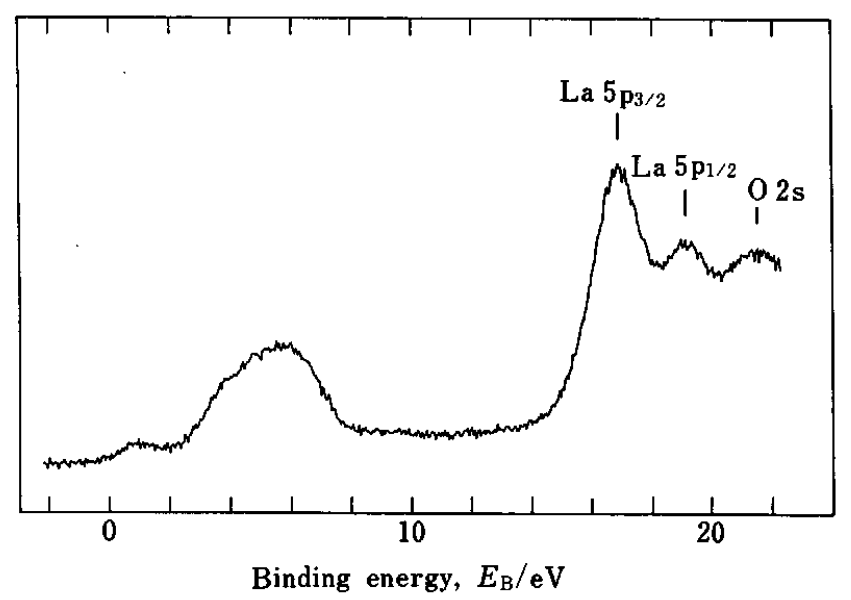

Fig. 5 X-Ray photoelectron spectrum of valence band for $\mathrm{LaCrO}_{4}$.

The atomic charges distributed over the $\mathrm{CrO}_{4}{ }^{3-}$ cluster were calculated to be +2.4 for $\mathrm{Cr}$ and -1.3 for $\mathrm{O}$, showing that the charges on $\mathrm{O}^{2-}$ are flowing into $\mathrm{Cr}^{5+}$. The overlap charge between $\mathrm{Cr}$ ion and $\mathrm{O}$ ion is positive, 0.1176 . The results indicate that covalency plays a significant role in the $\mathrm{Cr}-\mathrm{O}$ bonds of the $\mathrm{CrO}_{4}$ tetrahedral structure in $\mathrm{LaCrO}_{4}$. These features agree with the results of XPS measurements. This behavior of the $\mathrm{Cr}-\mathrm{O}$ bond was considered to contribute to stabilizing $\mathrm{CrO}_{4}{ }^{3-}$ tetrahedra.

The theoretical ionization energies calculated at the ROHF level were compared with the measured valence band spectrum, as shown in Table 2. Due to the assumptions used in the calculations, the absolute energy values are slightly different from the observed peak positions ( $c f . \mathrm{O} 2 \mathrm{~s}$ ), however, it is still possible to assign the measured bands as in the table. It should be noted that the assignment of $O 2 p$ non-bonding levels is not certain: they may be present in the weak peak just below the Fermi edge or included in the large peak. If included in the large peak, the weak peak may be assigned 


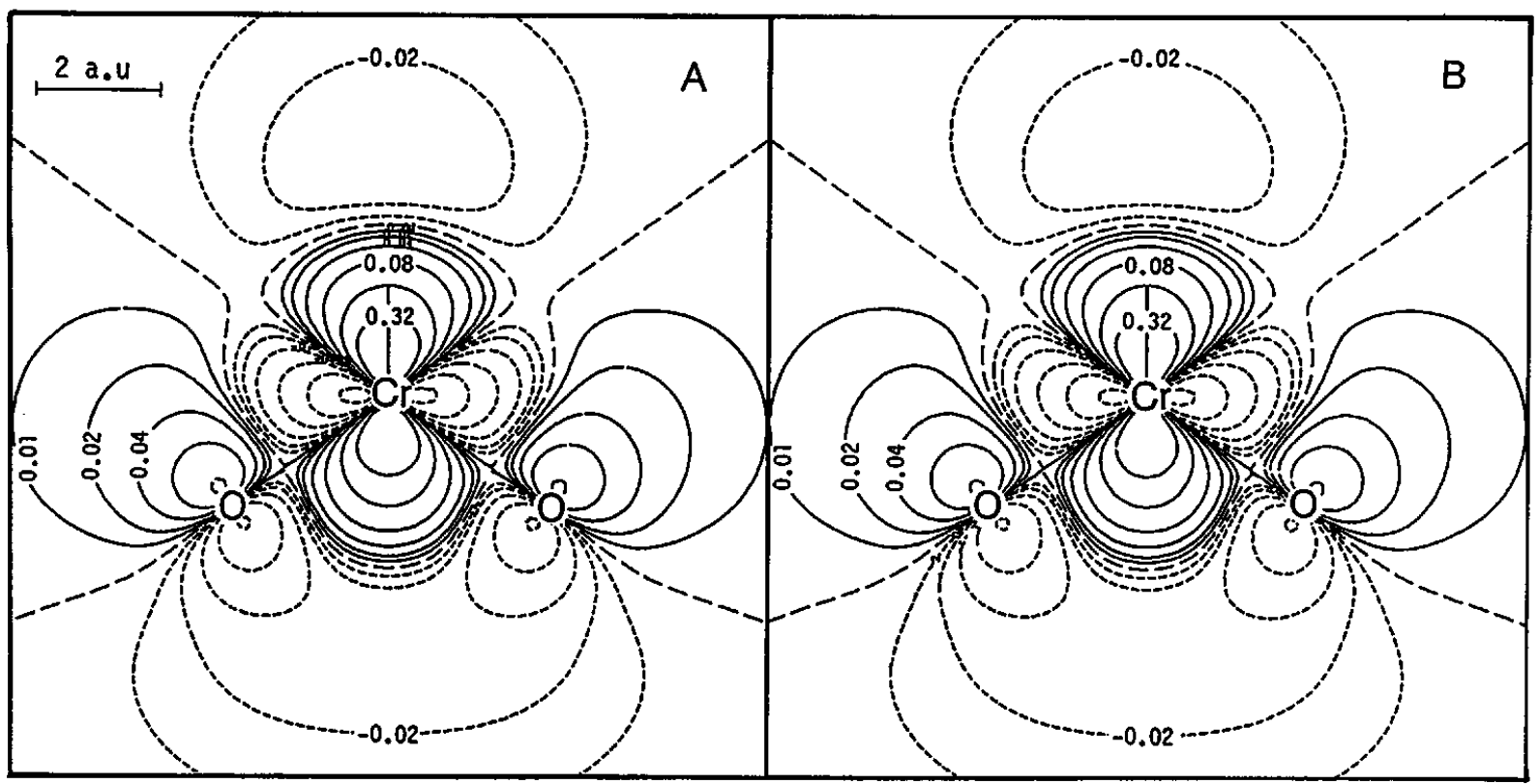

Fig. 6 Molecular orbital contour maps for the spin orbital of $\mathrm{CrO}_{4}{ }^{3-}$ cluster. Solid and broken lines indicate positive and negative amplitudes of wave function. The values are calculated at the ROHF level. (A) XZ plane and (B) YZ plane.

Table 2 Calculated energy levels in the valence band in $\mathrm{eV}$

\begin{tabular}{ccl}
\hline \multicolumn{1}{c}{ Calculated values } & Experimental peak positions & \multicolumn{1}{c}{ Assignment } \\
\hline 0.99 & 0.5 & O 2p non-bonding (and/or \\
$1.05,1.05$ & -2 & Cr 3d unpaired electron) \\
$2.41,2.43,2.45,2.45$ & $2.5-7.5$ & O 2p-Cr 3d bonding \\
$5.18,5.59,5.60,5.66$ & 16.9 & $\mathrm{Cr} \mathrm{3d-O} \mathrm{2p} \mathrm{bonding}$ \\
& 19.1 & La $5 \mathrm{p}_{3 / 2}$ \\
& 21.4 & La $5 \mathrm{p}_{1 / 2}$ \\
$22.92,22.92,22.92,23.58$ & $\mathrm{O} \mathrm{2s}$ \\
\hline
\end{tabular}

a. Electrons distribute mainly on the oxygen atoms. b. Electrons distribute mainly on the chromium atom.

to a 3d unpaired electron level.

\section{References}

1. H. Schwartz, Z. Anorg. Allge. Chem., 322, 1 (1963).

2. A. Roy and K. Nag, J. Inorg. Nucl. Chem., 40, 1501 (1978).

3. JCPDS 36-93.

4. L. Lavielle and H. Kessler, J. Electron Spectrosc. Relat. Phenom., 8, 95 (1976).

5. A. Furusaki, H. Konno and R. Furuichi, Nippon Kagaku Kaishi, 1992, 612.

6. D. A. Shirley, Phys. Rev., B5, 4709 (1972).

7. S. Tougaard, Surf. Interface Anal., 11, 453 (1988).

8. H. Kashiwagi, T. Takada, E. Miyoshi, S. Obara and F. Sasaki, ab-initio RHF calculation program, JAMOLA (1988).

9. C. C. J. Roothan, Rev. Mod. Phys., 32, 179 (1960).

10. "Physical Science Data", Vol. 16, ed. S. Huzinaga, Else- vier, Amsterdam, 1984.

11. T. Clark, J. Chandrasekhar, G. W. Spitznagel and P. V. R. Schleyer, J. Comput. Chem., 4, 294 (1983).

12. T. Koopmans, Physica, 1, 104 (1933).

13. R. J. Buenker and Peyerimhoff, Theor. Chim. Acta, 35, 33 (1974); A. Murakami, H. Iwaki, H. Terashima, T. Shoda, T. Kawaguchi and T. Noro, MR-SD-CIprogram, MICA3, 1985.

14. e.g. I. Ikemoto, K. Ishii, S. Kinoshita, H. Kuroda, M. A. Alario Franco and J. M. Thomas, J. Solid State Chem., 17, 425 (1976).

15. W.-Y. Howng and R. J. Thorn, J. Phys. Chem. Solids, 41, $75(1980)$.

16. C. D. Wagner, "Practical Surface Analysis, 2nd ed.", eds. M. P. Seah and D. Briggs, pp. 595, 645, John Wiley, New York, 1990.

17. H. Berthou, C. K. J $\phi$ rgensen and C. Bonnelle, Chem. Phys. Lett., 38, 199 (1976).

18. W.-Y. Howng and R. J. Thorn, Chem. Phys. Lett., 56, 463 
(1978).

19. P. Burroughs, A. Hamnett, A. F. Orchard and G. Thornton, J. Chem. Soc. Dalton Trans, 1976, 1686.

20. J. H. Scofield, J. Electron Spectrosc. Relat. Phenom., 8, 129 (1976).

21. K. Asami and K. Hashimoto, Corr. Sci., 17, 559 (1977).
22. H. Konno, J. Metal Finish. Soc. Jpn., 29, 425 (1978).

23. R. W. G. Wyckoff, "Crystal Structures, 2nd ed.", Vol. 3, Interscience, New York, 1965.

(Received May 18, 1992)

(Accepted June 25, 1992) 